\title{
SCHOOL ENVIRONMENT VERSUS HOME ENVIRONMENT - COMPARISON OF SELECTED PARAMETERS OF CHILDREN PHYSICAL ACTIVITY
}

\author{
Jarosław Herbert \\ University of Rzeszów, Faculty of Physical Education, Poland \\ Address for correspondence: \\ Jarosław Herbert \\ University of Rzeszów, Faculty of Physical Education \\ Towarnickeigo Street 3c, 35-959 Rzeszów, Poland \\ E-mail: jherbert@ur.edu.pl
}

\begin{abstract}
Ahstract In recent years research have shown a significant decrease in physical activity (PA) among young population. Increasingly carried out diagnosis of physical activity at different stages of our lives, with particular regard to children and adolescents indicates that with age, level of physical activity, especially in leisure time is reduced. The purpose of the research is to compare the selected parameters of physical activity during one day among students aged 6-8 years old. The study was conducted with use of the accelerometer ActiGraph WGT3X on group of 54 children ( $30-$ school and $24-$ kindergarten). Analysis shows that for such parameters as MET's, Vigorous, Total MVPA and Steps Counts one observed difference between the stay at school and sometimes school has statistical significance $(p<0.05)$.

On the basis of the studies carried out it is shown that the school environment helps to increase physical activity among children in school and the fact is that these children are more active.
\end{abstract}

Key worlls physical activity, accelerometer, school, kindergarten, WGT3X

\section{Introduction}

Previous studies show that among young people a significant decrease in physical activity is noted (PA) (Dumith, Gigante, Domingues, Kohl, 2011). Physical activity tends downward according to age throughout childhood and adolescence (Corder, Oglivie, Van Sluis, 2009, Dumith et al., 2011). Moreover, inactive children may become inactive adults, which in turn causes the higher risk of health complications in future life. Growing evidence of the health benefits of PA (Guinhouya, Samouda, Zitouni, Vilhelm, Hubert, 2011) have resulted in a growing need to understand the behaviour of PA and its patterns among children and adolescents. Previous cross - sectional studies among children and adolescents in physical activity, time spent in school and out of school have been carried out, among others, by such authors as: (Cox, Schofield, Greasley, Kolt, 2006; Tudor-Locke, Lee, Morgan, Beighle, Pangrazi, 2006). In many countries, increasingly guided diagnosis of physical activity at different stages of 
life is promoted with particular emphasis on children and adolescents. It shows that according to age, the level of physical activity, especially during leisure time decreases (Brettschneider, Naul, 2004).

The creation of habit in physical activity should be already started at kindergartens and primary schools and physical education should be focused on the support of physical development. In addition, physical education plays an important role in meeting the needs of pupils from their early childhood and prepares them for the life in a society.

In the entire range of physical education an important role is fulfilled by the movement habits which have longterm impact on the human health and they should be shaped during the early development of children. That is why it is crucial to educate children in terms of the importance of health and leisure activities from their early childhood. If children are exposed to the adverse health risks at an early age, they have the tendency to maintain this type of behaviour during their puberty and adulthood, eventually leading to an increased risk of many chronic diseases.

Physical activity of children in Poland against the background of European children is at an average level and should be raised.

\section{Material and methods}

The purpose of the research is comparison and diagnosis of selected parameters of physical activity during the day amongst children at the age of $6-8$ years with the use of accelerometer WGT3X. The day was divided into two segments of time: time spent at school (from 8 am to $2 \mathrm{pm}$ ) and time spent in the house (from $2 \mathrm{pm}$ to $8 \mathrm{pm}$ ). On the base of the literature review research questions were constructed.

1. Is there a difference in physical activity (selected parameters) between pupils from school and from kindergarten?

2. Which part of the day (school and kindergarten and time spent outside of the facility) is more active?

Research diagnosis in physical activity of students aged 6-8 years was carried out in the selected school ( 30 children) and in the kindergarten (24) in Rzeszów (southern Poland) in 2016 (26 girls and 28 boys). As a basis for determining the groups there was adopted a regular and active participation in school activities (mainly with physical education or elements of rhythm, gymnastics in kindergarten), observations and opinions of teachers. The research has been carried out on Mondays and Wednesdays, so that they were as similar as possible to each other in terms of the number of hours spent at school and the type of activities. Measurement was performed once.

The measurement was made by the author, then it was analysed with the use of the specialized software Actilife (Actigraph).

For research the diagnostic device Accelerometer WGT3X-BT ActiGraph (WGT3X, Pensacola, 2014) was used. The use of accelerometer devices is a valuable supplement to the survey methods in study concerning level of physical activity (Herbert, Czarny, 2013). The analysed parameters: sedentary, light, moderate, vigorous physical activity and steps count.

\section{Statistical methods}

The analysed parameters (variables) were presented using basic statistical measures: mean and standard deviation. In order to verify the statistical significance of differences between the two medium-sized, test of order pairs of Wilcoxon was used. 


\section{Research results}

Tahle 1. The results of physical activity parameters in kindergarten

\begin{tabular}{|c|c|c|c|c|c|c|c|c|}
\hline & & $\bar{x}$ & $x_{\min }$ & $x_{\max }$ & sd & V & $d$ & $p$ \\
\hline \multirow{2}{*}{ Sedentary } & school & 35.1 & 19.7 & 51.5 & 6.9 & 19.6 & \multirow{2}{*}{-1.8} & \multirow{2}{*}{0.057} \\
\hline & home & 36.9 & 14.3 & 56.3 & 9.6 & 26.0 & & \\
\hline \multirow{2}{*}{ Light } & school & 18.7 & 7.2 & 31.5 & 4.7 & 25.3 & \multirow{2}{*}{1.6} & \multirow{2}{*}{$0.008^{\circ}$} \\
\hline & home & 17.1 & 2.7 & 34.8 & 5.9 & 34.6 & & \\
\hline \multirow{2}{*}{ Moderate } & school & 5.2 & 0.3 & 16.7 & 3.0 & 57.6 & \multirow{2}{*}{0.1} & \multirow{2}{*}{0.388} \\
\hline & home & 5.0 & 0.2 & 18.8 & 4.1 & 80.6 & & \\
\hline \multirow{2}{*}{ Vigorous } & school & 1.0 & 0.0 & 6.0 & 1.1 & 106.0 & \multirow{2}{*}{0.1} & \multirow{2}{*}{0.197} \\
\hline & home & 1.0 & 0.0 & 9.7 & 1.4 & 145.8 & & \\
\hline \multirow{2}{*}{ Steps Counts } & school & 885.1 & 223.0 & 2561.0 & 470.5 & 53.2 & \multirow{2}{*}{27.6} & \multirow{2}{*}{0.182} \\
\hline & home & 857.5 & 62.0 & 2908.0 & 656.4 & 76.6 & & \\
\hline
\end{tabular}

* Statistical significance $(\alpha=0.05)$.

Shortcuts: $x$-average, $x_{\min }$ - minimum value, $x_{\max }$ - maximum value, $s d$ - standard deviation, $V$ - coefficient of variation, $d$ - difference between home and school, $p$ - probability test.

Source: authors' elaboration.

Tahle 2. The results of physical activity parameters at school

\begin{tabular}{|c|c|c|c|c|c|c|c|c|}
\hline & & $\bar{x}$ & $x_{\min }$ & $x_{\max }$ & sd & V & $d$ & $p$ \\
\hline \multirow{2}{*}{ Sedentary } & school & 35.1 & 19.7 & 51.5 & 6.9 & 19.6 & \multirow{2}{*}{-1.8} & \multirow{2}{*}{0.057} \\
\hline & home & 36.9 & 14.3 & 56.3 & 9.6 & 26.0 & & \\
\hline \multirow{2}{*}{ Light } & school & 18.7 & 7.2 & 31.5 & 4.7 & 25.3 & \multirow{2}{*}{1.6} & \multirow{2}{*}{$0.008^{\circ}$} \\
\hline & home & 17.1 & 2.7 & 34.8 & 5.9 & 34.6 & & \\
\hline \multirow{2}{*}{ Moderate } & school & 5.2 & 0.3 & 16.7 & 3.0 & 57.6 & \multirow{2}{*}{0.1} & \multirow{2}{*}{0.388} \\
\hline & home & 5.0 & 0.2 & 18.8 & 4.1 & 80.6 & & \\
\hline \multirow{2}{*}{ Vigorous } & school & 1.0 & 0.0 & 6.0 & 1.1 & 106.0 & \multirow{2}{*}{0.1} & \multirow{2}{*}{0.197} \\
\hline & home & 1.0 & 0.0 & 9.7 & 1.4 & 145.8 & & \\
\hline \multirow{2}{*}{ Steps Counts } & school & 885.1 & 223.0 & 2561.0 & 470.5 & 53.2 & \multirow{2}{*}{27.6} & \multirow{2}{*}{0.182} \\
\hline & home & 857.5 & 62.0 & 2908.0 & 656.4 & 76.6 & & \\
\hline
\end{tabular}

* - statistical significance $(\alpha=0.05)$.

Shortcuts: $x$-average, $x_{\min }-$ minimum value, $x_{\max }$ - maximum value, $s d$ - standard deviation, $V$ - coefficient of variation, $d$-difference between home and school, $p$ - probability test.

Source: authors' elaboration.

In the analysis of typically sedentary activities in kindergarten (intensity of not more than $2 \mathrm{METs}$ ) it is noted that the highest levels of this variable is recorded at the end of the day in home (between $5 \mathrm{pm}-7 \mathrm{pm}$ ), the total of $60 \%$ of the time during the entire test. In turn, at school the highest levels of this variable is at the beginning of the day (between 8:00 am-10:30 am) and the total of $54 \%$ of the time during the entire test. 


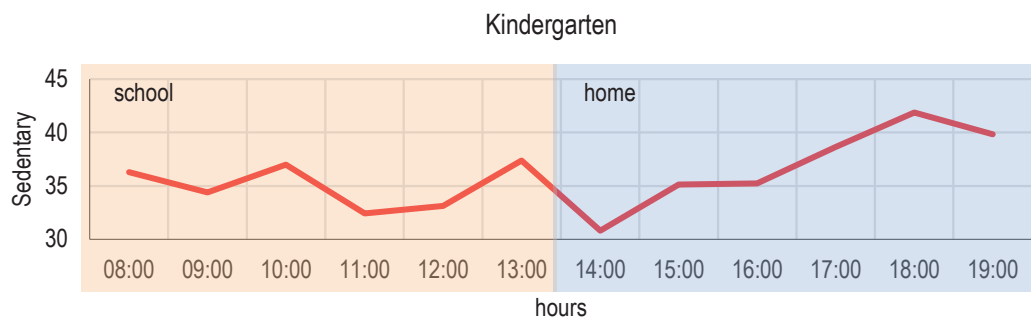

School

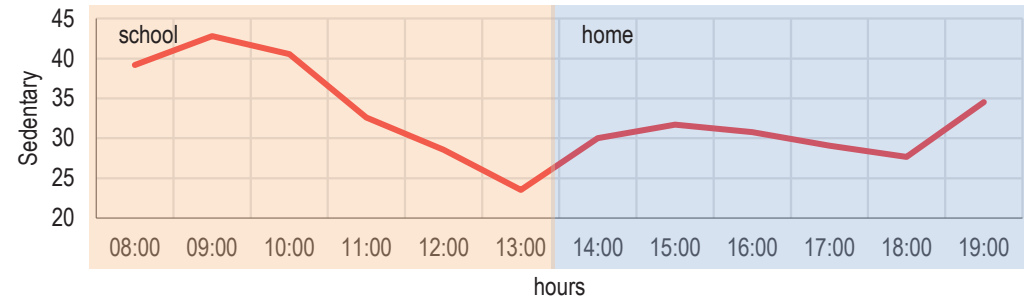

Figure 1. Sedentary behaviour of children during education time and in the house between $8 \mathrm{am}-8 \mathrm{pm}$

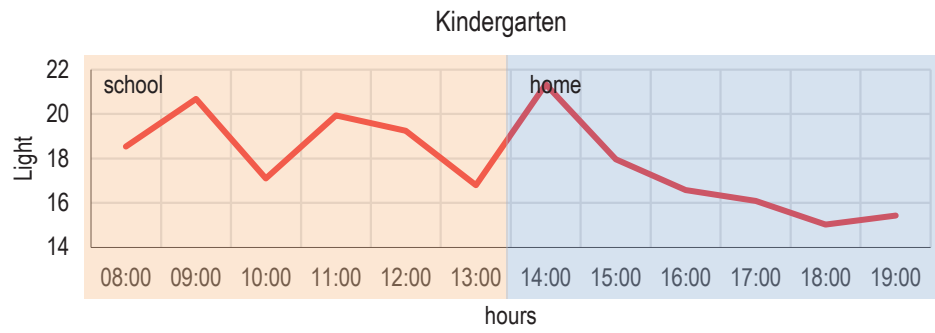

School

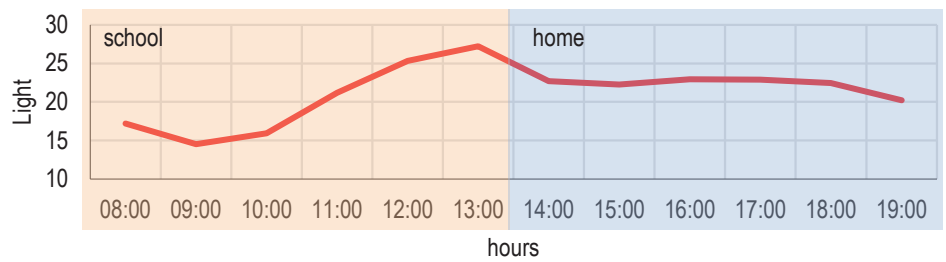

Figure 2. Light behaviour of children during education time and in the house between 8 am-8 pm

The course of the average value of light efforts (intensity range from 3 to $6 \mathrm{METs}$ ) indicates that throughout the duration of stay in kindergarten, this parameter has some fluctuations and is maintained at higher altitude in relation to the hours of the afternoon. It gives us approximately $30 \%$ of the time that was spent in this way. The school has 
a slightly opposite tendency where this parameter remains at a lower level during the school education to achieve its peak about $1 \mathrm{pm}$ and so remains until the end of the test. It gives us nearly $35 \%$ of the time that was spent in this way.

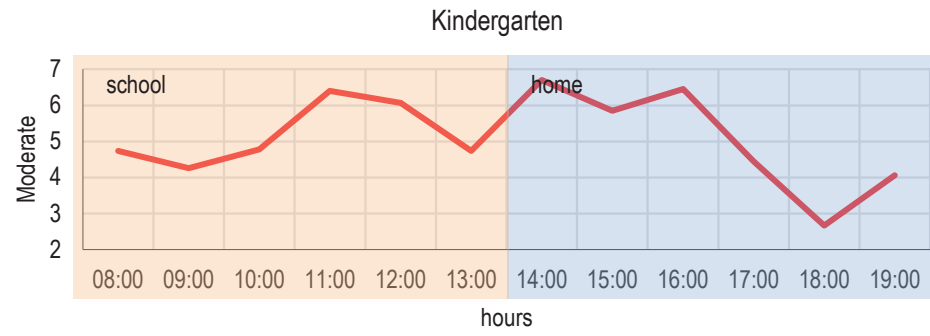

School

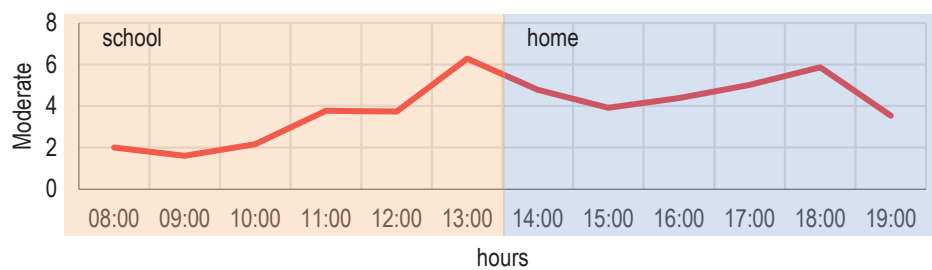

Figure 3. Moderate bahaviour of children during education and in the house between 8 am-8 pm

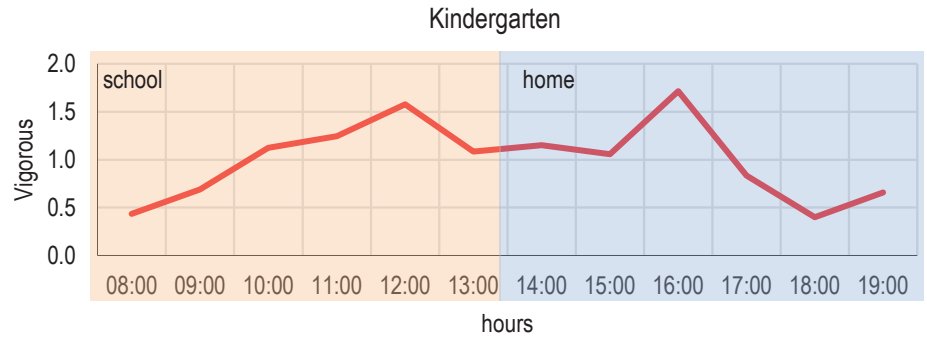

School

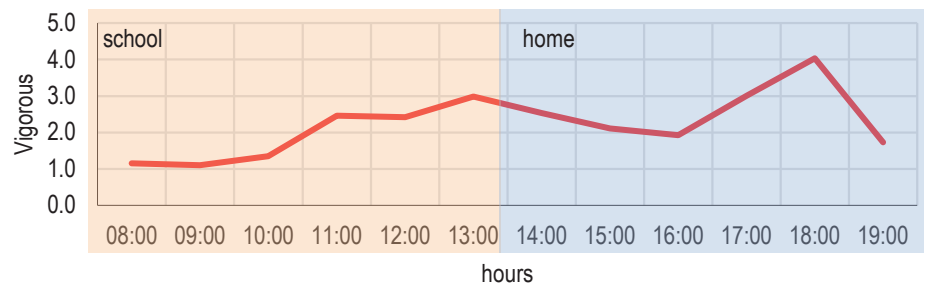

Figure 4. Vigorous behaviour of children during education and in the house between 8 am-8 pm 
When analysing the moderate efforts it is noted that in kindergarten this parameter increases gradually from 10 a.m. and is on the same level until $4 \mathrm{pm}$, that gives approximately a total of $8 \%$ of the time spent in this way. In turn, in school this parameter remains almost constant throughout the study time and this gives almost $6.5 \%$ of the time spent in this way.

Analysing the efforts at a very high intensity, it is noted that this parameter in the kindergarten is growing with the start of classes, it takes place around $12: 30 \mathrm{pm}$ to maintain more or less stable and at about $5 \mathrm{pm}$ it gradually decreases. This gives us approximately $2 \%$ of the time spent in this way. In turn, at school this parameter remains almost constant throughout the study time with a slight tilt at $6 \mathrm{pm}$ and this gives almost $4 \%$ of the time spent in this way.
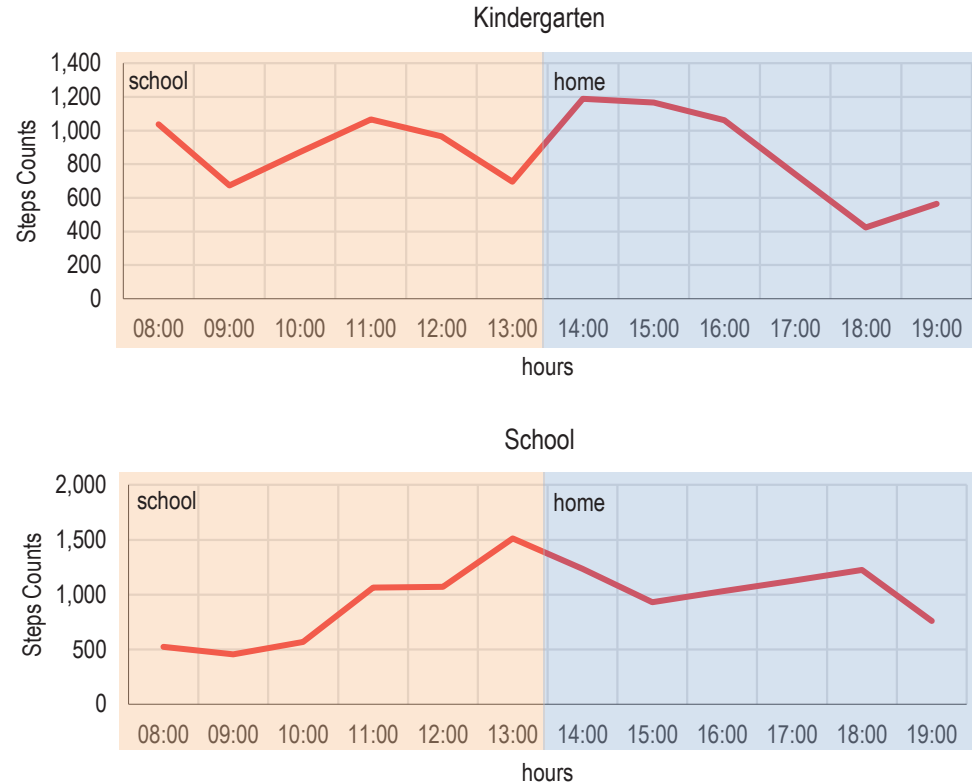

Figure 5. Distribution of the amount of steps children during education time and in the house between $8 \mathrm{am}-8 \mathrm{pm}$

In the case of the number of steps in the kindergarten this parameter increases quickly from the start of the test, with small fluctuations until $4 \mathrm{pm}$, to decrease in the afternoon time. The average number of children's steps is 9,700 . In the school it is growing much slower, to achieve culmination at $1 \mathrm{pm}$, thus maintaining the similar value until $6.30 \mathrm{pm}$. The average number of steps is 11,500 .

\section{Discussion}

By comparing other results in this area of research (Steele et al., 2010; Carson, Cliff, Janssen, Okely, 2013; Telford et al., 2013), it can vary for example in terms of: division of the day during test, duration of test, sex, and not significant differences of test equipment (various accelerometers, pedometers, phone applications). In the selected parameters there are no significant differences. But one can see that children at school and kindergarten spend 
their time more actively despite the forced sitting position between $8 \mathrm{am}-1 \mathrm{pm}$. The reason for the increased activity may be so called spontaneous activity. In turn, children from kindergarten despite the greater amount of time spent on the active games often present sedentary behaviours. According to the analysed parameters (sedentary activities, light and moderate one) one can see some common features among tested group in the school, where the parameters remain stable, and in kindergarten these behaviours are subjected to some fluctuations during the day (moderate and high-intensity one). In the United Kingdom a tested group of 9-10 years old children indicated greater physical activity out of the school. This may be caused by the break in the studies from 7 am to 10.00 am (Steele et al., 2010). Sedentary activities in tests (Telford et al., 2013) remained at the level of $40 \%$ of the spent time during the day. It is worth adding, that in those studies, the respondents were in the age range from 8-12 years. In turn, in the tests (Carson, Cliff, Janssen, Okely, 2013) the average while staying at school was about $35 \%$ of spent time, and after school about $29 \%$. Studies of the author indicate that in case of kindergarten it was $35 \%$, school $-33 \%$, which seems to be the better result. Efforts at a very high intensity take place more frequently at school. For a comparison of the studies (Thompson et al., 2009) the average was 3.5, in turn in the tests (Russell et al., 2006) the average was around 5.0. In these studies, one can note a lower level of high-intensity activity, which is a result of sedentary form of classes (kindergarten - an average of 1.5 and the school - average of 2). It is observed that in time out of school, kindergarten the value of this parameter slightly increases.

About $84 \%$ of the intervals observed indoors in preschool, are characterized by sedentary behaviour (Brown et al., 2009). Regarding the environment for physical activity, the assessments of the physical space of preschools by direct observation, higher total scores consecutively reported higher values of physical activity in relation to low scores (Bower et al., 2009). This fact demonstrates the positive influence of the environment conducive to the practice of physical activity in preschools.

The recommended number of steps per day is minimum 10,000 (Hills, Mokhtar, Byrne, 2014). Children and young people should make 12,000 steps per day. In turn, Tudor-Locke (Tudor-Locke, Lee, Morgan, Beighle, Pangrazi, 2006; Tudor-Locke et al., 2011) write that boys should make 13,000-15,000 steps a day and girls 11,00012,000 steps a day. The results of Step Counts were much higher (kindergarten - 9,700 on average, school - 11,500 on average) than in the studies of Vale (Vale, Trost, Duncan, Mota, 2015) where boys made 9,225 steps a day and girls 9,177 steps a day, and Gabel (et al. 2012) - 8,968 steps per day on average. Otherwise, according to Pagels, Boldemann, Raustorp (2011) 7,313 steps a day on average and only in the tests (Tanaka, Tanaka, 2011) they were much higher and gave the result at the level of 13,000 steps per day on average. The research involves the need for attempt to answer the research questions on the material. According to research, there is small difference in physical activity between pupils from the school and from the kindergarten, with the benefit of pupils from school. It is the most visible in the number of steps, where children from school achieved much better results (11,500 steps) than children from kindergarten ( 9,700 steps). One can also point out at time intervals between tested groups, where a moderate and higher intensity activity increases and it is maintained by children at school in the afternoon. In turn, in preschool children one will see a large drop from the $4 \mathrm{pm}$ in these parameters. Another research question was supposed to answer the question which part of the day is more active. Parameter analysis of moderate activity indicates the same level in both groups, in turn, higher-intensity activity parameter is higher in the afternoon among children at school.

The need for diagnosis and monitoring of physical activity should be pointed out. 
New opportunities in this aspect create objective methods for measuring with the use of so-called motion sensors (pedometers), acceleration measures (accelerometers), devices for monitoring physiological parameters (heart rate monitor) as a support, and later as well as alternatives for research questionnaires

At the time of the introduction of accelerometers for research on physical activity in the world, research groups were small due to the small number of devices. Every year, the number of these devices increased. This is mainly dictated by the amount of equipment. The author began his research in 2013 with one device. Today, he has 15 devices at his disposal and he cooperates with the medical department of the University of Rzeszów, which owns about 60 devices.

\section{Conclusions}

On the base of the studies carried out, the following conclusions were constructed:

1. There is more physical activity at school (parameters - vigorous acitivity and counts steps) compared to kindergarten.

2. Time spent in kindergarten and school (parameters - vigorous acitivity and counts steps) is more active than time spent at home.

3. It was noted that during the stay at school / kindergarten children are characterized by higher level of physical activity.

\section{Acknowledgements}

Work done in statutory research at the University of Rzeszów, Faculty of Physical Education (number 507/1).

\section{Referenences}

Bower, J.K., Hales, D.P., Tate, D.F., Rubin, D.A., Benjamin, S.E., Ward, S.E. (2008). The Childcare Environment and Children's Physical Activity. Am J Prev Med, 34, 23-29.

Brettschneider, W.D., Naul, R. (2004). Final report on „Study on young people's lifestyles and sedentariness and role of sport in the context of education and as a means of restoring the balance. Paderborn.

Brown, W.H., Pfeiffer, K.A., Mclver, K.L., Dowda, M., Addy, C.L., Russell, R.P. (2009). Social and environmental factors associated with preschoolers' non sedentary physical activity. Child Dev., 80, 45-58.

Carson, V., Cliff, D.P., Janssen, X., Okely, A.D. (2013). Longitudinal levels and bouts of sedentary time among adolescent girls. BMC Pediatrics, 13, 173.

Corder, K., Ogilvie, D., Van Sluijs, E.M. (2009). Invited commentary: physical activity over the life course - whose behavior changes, when, and why?" Am J Epid, 170, 1078-1081.

Cox, M., Schofield, G., Greasley, N., Kolt, GS. (2006). Pedometer steps in primary school-aged children: a comparison of school-based and out-of-school activity. J Sci Med Sport, 9, 91-97.

Dumith, S.C., Gigante, D.P., Domingues, M.R., Kohl, H.W. (2011). 3rd. Physical activity change during adolescence: a systematic review and a pooled analysis. Int J Epidemiol, 40, 685-698.

Gabel, L.A., Proudfoot, N.A., Obeid, J., MacDonald, M.J., Bray, S.R., Cairney, J., Timmons B.W. (2012). Step Count Targets Corresponding to New Physical Activity Guidelines for the Early Years. Medicine and Science in Sports and Exercise, 45, 314-318.

GT3X+ and WGT3X+ Device Manual. (2014). The ActiGraph, Pensacola.

Guinhouya, B.C., Samouda, H., Zitouni, D., Vilhelm, C., Hubert, H. (2011). Evidence of the influence of physical activity on the metabolic syndrome and/or on insulin resistance in pediatric populations: a systematic review. Int J Pediatr Obes, 6, 361-388.

Herbert, J., Czarny, W. (2013) Accelerometer wgt3x addition to studies of physical activity. Scientific Review of Physical Culture, 3 (3), 167-172. 
Hills, A.P., Mokhtar, N., Byrne, N.M. (2014). Assessment of physical activity and energy expenditure: an overview of objective measures. Frontiers in Nutrition, 1, 5. DOI: 10.3389/fnut.2014.00005.

Janssen, I., Leblanc, A.G. (2010). Systematic review of the health benefits of physical activity and fitness in school-aged children and youth. Int J Behav Nutr Phys Act, 7, 40.

Pagels, P., Boldemann, C., Raustorp, A. (2011). Comparison of pedometer and accelerometer measures of physical activity during preschool time on 3-to 5-year-old children. Acta Pediatric, 100, 116-120.

Russell, R., Stevens, J., Pratt, C., Sallis, J., Schmitz, K., Webber, S., ..., Young, D. (2006). Objectively Measured Physical Activity in Sixth-Grade Girls. Arch Pediatr Adolesc Med, 160 (12), 1262-1268.

Steele, R.M., Van Sluijs, E.M., Sharp, S.J., Landsbaugh, J.R., Ekelund, U., Griffin, S.J. (2010). An investigation of patterns of children's sedentary and vigorous physical activity throughout the week. Int J Behav Nutr Phys, 7, 88.

Tanaka, C., Tanaka, S. (2009). Daily physical activity in Japanese preschool children evaluated by triaxial accelerometry: the relationship between period of engagement in moderate-to-vigorous physical activity and daily step counts. Journal of physiological anthropology, 28, 283-288.

Telford, R.M., Telford, R.D., Cunningham R.B., Cochrane T., Davey, R., Waddington, G. (2013). Longitudinal patterns of physical activity in children aged 8 to 12 years: the LOOK study. International Journal of Behavioral Nutrition and Physical Activity, 10, 81.

Thompson, A.M., McHugh, T.L., Blanchard, CH.M., Campagna, F.D., Durant, M.A., Rehman, L.A., Murphy, R.L., Wadsworth, L.A. (2009). Physical activity of children and youth in Nova Scotia from 2001/02 and 2005/06. Preventive Medicine, 49 (5), $407-409$.

Tudor-Locke, C., Lee, S.M., Morgan, C.F., Beighle, A., Pangrazi, R.P. (2006). Children's pedometer-determined physical activity during the segmented school day. Med Sci Sports Exerc, 38, 1732-1738.

Tudor-Locke, C., Craig, C.L., Beets, M.W., Raustrop, A., Rowe, D.A., Spence, J.C., ... Balir, S.N. (2011). How Many Steps/Day are Enough? for Children and Adolescents. International Journal of Behavioral Nutrition and Physical Activity, 8, 78.

Vale, S., Trost, S.G., Duncan, M.J., Mota, J. (2015). Step based physical activity guidelines for preschool-aged children. Preventive Medicine, 70, 78-82.

Cite this article aS: Herbert, J. (2018). School Environment versus Home Environment - Comparison of Selected Parameters of Children Physical Activity. Central European Journal of Sport Sciences and Medicine, 2 (22), 79-87. DOI: 10.18276/cej.2018.2-09. 